\title{
Analisis Bahan Ajar Pembelajaran Kacapi Bani Ambara Pada Mata Pelajaran Seni Budaya Di Sma Negeri 1 Ciamis
}

\author{
Alfin Nurul Azmi, Denden Setiaji, Arni Apriani \\ Universitas Muhammadiyah Tasikmalaya \\ Jl.Tamansari No. KM 2.5 Mulyasari Kec. Tamansari Tasikmalaya Jawa Barat Indonesia \\ Email:alfinazmi10@gmail.com
}

\begin{abstract}
ABSTRAK
Di SMAN 1 Ciamis terdapat pembelajaran Seni Budaya yang di dalamnya mempelajari pembelajaran seni musik khusunya musik tradisional. Dimana setiap siswa harus mempelajari memainkan alat musik khas jawa barat yaitu Kacapi. SMAN 1 Ciamis ini menjadi satu-satunya sekolah menengah atas di daerah Ciamis yang mempelajari alat musik tradisional dalam pembelajaran Seni Budaya di kelas khususnya dalam praktik memainkan alat musik kecapi menggunakan kacapi kawih. Berkaitan dengan pembelajaran Kacapi dalam mata pelajaran Seni Budaya di SMAN 1 Ciamis, peneliti merasa tertarik untuk meneliti bagaimana bahan dan materi ajar yang di susun oleh guru Seni Budaya agar bisa mencapai tujuan pembelajaran. Karena pembelajaran Kacapi ini jarang diajarkan di sekolah-sekolah umum lainya. Dengan harapan hasil penelitian ini bisa memotivasi sekolah lainya agar terus mengembangkan pembelajaran pada mata pelajaran Seni Budaya dan dapat menambah pengetahuan bagi bidang pendidikan seni khususnya seni musik. Penelitian ini menggunakan metode deskriptip dengan pendekatan kualitatif. Peneltian ini dilakukan di SMAN 1 Ciamis yang berlokasi di Jalan Gunung Galuh No. 37, Kecamatan Ciamis, Kabupaten Ciamis, Jawa Barat. Adapun sumber data yang digunakan adalah dengan melakukan observasi, wawancara, studi dokumentasi dan studi literature. Kemudian data akan dianalisis menggunakan teknik analisis pendalaman kajian dengan langkah-langkah mereduksi data, penyajian data dan menarik kesimpulan. Berdasarkan analisis data yang dilakukan, diperoleh kesimpulan bahwa bahan ajar dalam pembelajaran kacapi kawih di SMAN 1 Ciamis sudah sesuai dengan kurikulum tingakat Sekolah Menengah Atas. Dan bahan ajar pembelajaran kacapi kawih tersebut berupa modul pembelajaran dengan materi ajar Etude kacapi yang dibuat sendiri oleh guru Seni Budaya dengan adaptasi dari Etude kacapi Mang Koko yang disederhanakan.
\end{abstract}

Kata Kunci : Bahan ajar, Pembelajaran, Kacapi

\begin{abstract}
In SMAN 1 Ciamis there is learning Art and Culture in which learning the art of traditional music. Where every student must learn to play a typical musical instrument of West Java, Kacapi. SMAN 1 Ciamis is the only high school in ciamis area that learns traditional musical instruments in learning Art and Culture in the classroom, especially in the practice of playing harp instruments using kacapi kawih. Related to Kacapi's learning in Art and Culture subjects at SMAN 1 Ciamis, researchers are interested in researching how materials and teaching materials are arranged by Art and Culture teachers in order to achieve learning objectives. Because Kacapi learning is rarely taught in other public schools. With the hope that the results of this research can motivate other schools to continue to develop learning in arts and culture subjects and can increase knowledge for the field of art education, especially music arts. This research uses descriptor method with qualitative approach. This research was conducted at SMAN 1 Ciamis located at Jalan Gunung Galuh No. 37, Ciamis District, Ciamis Regency, West Java. The data source used is by conducting observations, interviews, documentation studies and literature studies. Then the data will be analyzed using research deepening analysis techniques with steps to reduce data, present data and draw conclusions. Based on the data analysis conducted, it was concluded that the teaching materials in kacapi kawih learning at SMAN 1 Ciamis are in accordance with the curriculum of high school level. And the teaching material of kacapi kawih learning is a learning module with etude kacapi teaching materials made by art and culture teachers with an adaptation of the simplified Etude kacapi Mang Koko.
\end{abstract}

Keywords: Teaching Materials, Learning, Kacapi 


\section{A. Pendahuluan}

Dalam kegiatan belajar mengajar terdapat komponen pembelajaran yang dapat digunakan sebagai penunjang kegiatan pembelajaran. Komponen pembelajaran terdiri dari beberapa strategi pembelajaran salah satu strategi tersebut berhubungan dengan materi pembelajaran. Salah satu pendukung materi pembelajaran terdapat dalam sumber belajar atau bahan ajar. Bahan ajar harus mempertimbangkan sumber belajar dan pemilihanya harus sesuai dengan kurikulum yang digunakan agar tujuan pembelajaran dapat tercapai. Dari setiap mata pelajaran yang ada di satuan pendidikan sudah pasti memiliki dan menggunakan bahan ajar dengan materi yang berbeda sesuai dengan guru dan mata pelajaran yang diampunya. Biasanya guru bertugas menggunakan materi ajar yang relevan, efektif dan juga isinya sesaui dengan kurikulum.

Di SMAN 1 Ciamis terdapat pembelajaran Seni Budaya yang dalamnya mempelajari pembelajaran seni musik khsusunya musik tradisional. Dimana setiap siswa harus mempelajari memainkan alat musik khas jawa barat yaitu Kacapi. SMAN 1 Ciamis ini menjadi satu-satunya sekolah menengah atas di daerah Ciamis yang mempelajari alat musik tradisional dalam pembelajaran Seni Budaya di kelas. Di SMAN 1 Ciamis, khususnya dalam praktik memainkan alat musik kecapi ini menggunakan kacapikawih.

Dengan demikian pembelajaran Kacapi pada mata pelajaran Seni Budaya di SMAN 1 Ciamis menggunakan bahan dan materi ajar pembelajaran Kacapi khusus yang dibuat dan disusun oleh guru Seni Budaya di SMAN 1 Ciamis yaitu Bapak Bani Ambara dengan adaptasi dari materi ajar dan metode pembelajaran Kacapi Mang Koko yang disederhanakan dan tidak mengubah tujuan dari pembelajaran itu sendiri.

\section{B. Metode Penelitian}

Berdasarkan permasalahan yang diteliti dan sudah diuraikan, penelitian ini menggunakan metode deskriptif dengan pendekatan kualitatif. Penelitian dengan menggunakan metode deskriptif menggambarkan apa yang terjadi di lapangan.

Dengan begitu, kedudukan peneliti sebagai perencana, pelaksana, pengumpulan data, analis, penafsiran data, dan pada akhirnya peneliti melaporkan hasil penelitiannya. Selanjutnya peneliti mengkaji data-data faktual tentang bahan ajar yang digunakan di lapangan guna memunculkan hasil temuan yang dibutuhkan, kemudian mendeskripsikan hasil data dan temuan yang sudah dikaji sebelumnya.

Adapun tahapan pengolahan data dalam penelitian ini adalah sebagai beikut:

\section{Reduksi data}

Pada penelitian ini, peneliti melakukan pembatasan data dengan tujuan bahasan yang ada dalam penelitian ini tidak terlalu melebar.

\section{Display data (penyajian data)}

Dalam penelitian ini memakai pendekatan kualitatif deskriptif analitik. Oleh karena itu, penyajian data dilakukan dalam bentuk uraian singkat.

3. Pengambilan kesimpulan dan verifikasi data

Dalam penelitian ini, verifikasi data dilakukan dengan tujuan memeriksa data yang telah dikumpulkan dalam proses penelitian.

\section{Hasil Penelitian dan Pembahasan \\ 1. Gambaran SMAN 1 Ciamis}

Salah satu sekolah menengah atas favorit di kabupaten Ciamis adalah SMAN 1 Ciamis. Sekolah ini beralamat di 
Desa Ciamis, Kecamatan Ciamis, lebih tepatnya di Jalan Gunung Galuh No. 37, Kabupaten Ciamis. Berdekatan dengan Kantor Dinas Pendidikan Kabupaten Ciamis, Terminal Ciamis, Pasar Ciamis, Stadion Galuh, dan beberapa sekolah lainya di Ciamis.

Saat ini SMAN 1 Ciamis dipimpin oleh Drs. Wawan Haryawan, M.Pd. Bersumber dari website resmi sekolah (https://www.sman1ciamis.sch.id) Kepala sekolah menyampaikan dan memaparkan tentang SMAN 1 Ciamis. Dimana sekolah ini merupakan sekolah menengah atas satu-satunya di kabupaten Ciamis yang melaksanakan Program Rujukan. Sekolah Rujukan adalah sekolah yang telah memenuhi Standar Nasional Pendidikan, memiliki ekosistem yang baik, memiliki mutu yang baik, beriniovasi, dan berprestasi akademik maupun non akademik serta melaksanakan program pendidikan yang layak menjadi rujukan sekolah yang lain.

SMAN 1 Ciamis memiliki akreditasi $A$ yang dilihat dari website Kemendikbud. Sekolah ini menggunakan kurikulum tiga belas atau yang sering disebut dengan kurtilas. SMAN 1 Ciamis menerapkan system fullday dimana kegiatan siswa berada di sekolah sehari penuh yang dimulai dari pukul 07.00 dari hari senin sampai jumat.

Dari website Kemendikbud (http://sekolah.data.kemdikbud.go.id)

SMAN 1 Ciamis memilik Guru sebanyak 57 dan 1469 peserta didik yang terdiri dari siswa laki-laki dan perempuan, memiliki kelas 50 ruang, 3 labolatorium, perpustakaan, mesjid, kantin dan memiliki lapangan tertutup dan lapangan terbuka.

2. Kesesuaian bahan ajar pembelajaran

Kacapi Kawih Bani Ambara pada mata pelajaran Seni Budaya dengan kurikulum di SMAN 1 Ciamis.

Menurut Andi Prastowo dalam
Rusdiana (2011) menegaskan pemahaman bahan ajar sebagai segala bahan (baik informasi, alat, maupun teks) yang disusun secara sistematis, yang menampilkan sosok utuh dari kompetensi yang dikuasai peserta didik dan digunakan dalam proses pembelajaran dengan tujuan perencanaan dan penelaahan implementasi pembelajaran. Dari pengertian diatas dapat disimpulkan bahwa bahan ajar adalah perangkat yang memuat materi pembelajaran untuk mencapai tujuan dari pembelajaran sesuai dengan kompetensi yang ditentukan dan disusun.

Bahan ajar yang disusun harus memperhatikan kriteria bahan ajar berdasarkan teori-teori dari bahan ajar dimana bahan ajar harus sesuai dengan kompetensi-kompotensi yang terdapat dalam kurikulum. Kompetensikompetensi yang ada dalam bahan ajar ini dapat dilihat dari silabus yang digunakan. Menurut Masnur Muslich (2007: 23) menyatakan bahwa Silabus merupakan penjabaran standar kompetensi dan kompetensi dasar ke dalam materi pokok, kegiatan pembelajaran dan indikator pencapaian kompetensi untuk penilaian, alokasi waktu dan sumber belajar. Sesuai dengan pernyataan tersebut dapat diartikan bahwa kurikulum dan silabus saling berhubungan untuk memnentukan dan menyusun bahan ajar.

Silabus harus sesuai dengan kompetensi yang ada di sekolah dari segi materi yang dipelajari. Sesuai dengan pengertian di atas menurut Manshur Muslich dalam silabus memuat minimal tujuh komponen utama, yaitu standard kompetensi, kompetensi dasar, indikator, materi pembelajaran, penilaian, alokasi waktu, dan sumber belajar. 
Silabus pembelajaran kacapi kawih pada mata pelajaran Seni budaya di SMAN 1 Ciamis sudah memuat tujuh komponen dalam silabus, diantaranya memuat standard kompetensi, kompetensi dasar, indikator, materi pembelajaran, penilaian, alokasi waktu, dan sumber belajar. Dilihat dari kompetensi dasar yang ada di dalam silabus terdapat poin 3.1 yaitu memahami musik tradisional berdasarkan jenis dan fungsinya dan 4.1 yaitu memainkan musik tradisional kacapi kawih dengan membaca partiturnya. Dari kompentensi dasar terebut terlihat pengembangan dari kompetensi dasar aspek keterampilan yaitu memainkan alat musik tradisional kacapi. Hal ini sudah sesuai dengan pengembangan silabus dan kurikulum yang memperhatikan karakteristik sekolah dan ketersedian sarana dan prasarana di sekolah yaitu tentang ketersediaan alat musik tradisional kacapi yang memadai jika digunakan dalam pembelajaran dengan begitu hal tersebut bisa meningkatkan kualitas proses dan hasil dalam pembelajaran.

Dengan kesesuaian anatara silabus dengan kurikulum, maka dari itu bahan ajar yang disusun serta dibuat akan mengacu pada silabus. Menurut jenisnya bahan ajar dikelompokan menjadi empat bagian diantaranya bahan ajar cetak, bahan ajar dengan audio, bahan ajar dengan visual, dan bahan ajar interaktif. Sesuai dengan hasil penelitian bahan ajar yang digunakan dalam pembelajran kacapi kawih ini yaitu dengan modul, dimana modul ini termasuk pada jenis bahan ajar cetak.

Modul pembelajaran biasanya berisikan kompetensi dasar yang akan dicapai oleh peserta didik berikut materi pembelajaran yang dibuat dengan tujuan agar peserta didik bisa belajar secara mandiri. Terdapat komponen-komponen dalam modul pembelajaran diantaranya standard kompetensi, kompetensi dasar, tujuan pembelajaran, materi pembelajaran, uraian materi, dan latihanlatihan. Dari hasil penelitian modul pembelajaran yang dibuat oleh Bapak Bani Ambara sudah memuat semua dari komponen modul tersebut seperti yang tertera dalam hasil penelitian diatas.

Maka dari itu, dari hasil analisis kurikulum, silabus dan bahan ajar pembelajaran kacapi kawih pada mata pelajaran Seni budaya yang digunakan di SMAN 1 Ciamis bisa dikatakan sudah sesuai. Karena kesesuaian tersebut maka kompetensi dasar yang ada dalam modul pembelajaran bisa tercapai oleh para peserta didik bisa tercapai. Hal ini dibuktikan dari hasil penilaian guru Seni budaya SMAN 1 Ciamis tentang pembelajaran kacapi kawih ini. Penilaian dalam pembelajaran kacapi kawih menggunakan penilaian dengan melakukan tes praktek dalam memainkan kacapi kawih. Adapun nilai yang dihasilkan berupa nilai yang sesuai dengan kemampuan pesera didik.

\section{Bentuk materi pembelajaran Kacapi}

Kawih Bani Ambara pada mata pelajaran Seni Budaya di SMAN 1 Ciamis

Pada umumnya pembelajaran kacapi kawih menggunakan materi pembelajaran kacapi Mang Koko dengan berbenuk Etude yang terdiri dari Etude 1 sampai 53 dengan indikator sebagaimana dalam tabel hasil penelitian di atas. Namun demikian Etude Mang Koko ini mempunyai tingkat kesulitan yang cukup sulit dalam pembelajaranya jika diterapkan pada Sekolah Menengah Atas umum seperi di SMAN 1 Ciamis. Maka dari itu guru Seni budaya SMAN 1 Ciamis Bapak Bani Ambara membuat sendiri Etude pembelajaran kacapi kawih yang sederhana dengan mengadaptasi dari Etude kacapi Mang Koko. 
Dari hasil penelitian tentang Etude pembelajaran kacapi kawih Bani Ambara terlihat perbedaan yang signifikan dengan Etude Mang Koko karena dari Etude pembelajaran kacapi kawih Bani Ambara ini sangat disederhanakan supaya memudahkan peserta didik dalam mempelajarinya. Perbedaan tersebut bisa dilihat dari salah satu Etude yang sama, yang digunakan dalam pembelajaran kacapi kawih di SMAN 1 Ciamis yaitu Etude pola pirigan gelenyu catrik.

Etude pola pirigan gelenyu catrik dalam Etude Mang Koko yaitu terdapat pada Etude 16.

Etude 16

\begin{tabular}{|c|c|c|c|c|c|c|c|c|c|}
\hline B & $\dot{5}$ & $\ddot{i}$ & $\dot{5}$ & 3 & & $\dot{5}$ & $\ddot{i}$ & $\dot{5}$ & 3 \\
\hline A & 5 & $\mathrm{i}$ & 5 & $\overline{34}$ & & $\overline{5 i}$ & $\overline{5 i}$ & $\overline{54}$ & 3 \\
\hline B & $\dot{2}$ & $\mathrm{i}$ & $\dot{4}$ & 3 & 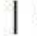 & $\dot{2}$ & $\mathrm{i}$ & 2 & $\ddot{2}$ \\
\hline A & 2 & 1 & $\overline{12}$ & $\overline{33}$ & I & $\overline{33}$ & $\overline{33}$ & $\overline{32}$ & 0 \\
\hline B & 5 & $i$ & 2 & 3 & 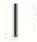 & 5 & i & $\dot{2}$ & 3 \\
\hline A & 5 & $\overline{15}$ & $\overline{12}$ & 3 & & 5 & $\overline{15}$ & $\overline{12}$ & $\overline{34}$ \\
\hline B & 5 & $\ddot{1}$ & 5 & 3 & & $\dot{5}$ & $\ddot{i}$ & $\dot{5}$ & 5 \\
\hline A & $J$ & $\overline{5 i}$ & $\overline{54}$ & & & 2 & $\overline{12}$ & $\overline{34}$ & 5 \\
\hline
\end{tabular}

Partitur 1. Etude kacapi Mang Koko 16

Pada Etude 16 Mang Koko ini merupakan etude pirigan gelenyu catrik dimana dilihat dari pola susuan pancer, kenong, dan goong sudah sesuai yaitu pola iringan 2-5. Dalam etude 16 Mang Koko ini susunan nada nya bervariatif dari mulai nada satu ketukan penuh, dan nada stengah (1/2 ketukan) dengan cara memainkanya menggunakan teknik di toel untuk jari telunjuk tangan kiri dan teknik disintreuk untuk jari telunjuk tangan kanan. Tingkat kesulitan dalam etude ini yaitu perbedaan memainkan antara tangan kiri dan tangan kanan, dimana perbedaan tersebut meliputi teknik memainkan tangan kiri dan kana yang berbeda, dan harga nada yang harus dimainkan oleh tangan kiri dan tangan kanan bereda.

Dalam memainkan etude 16 Mang Koko ini perlu konsentrasi, dan fokus yang lebih dikarenakan pada etude ini pola memainkan antara tangan kiri dan kanan berbeda. Dengan demikian dalam mempelajari Etude Mang Koko ini memerlukan alokasi waktu yang lama dalam pembelajaranya karena dilihat dari tingkat kesulitan dalam pembelajaranya.

Sedangkan Etude pembelajaran kacapi kawih Bani Ambara tentan pola pirigan gelenyu catrik ini sangat disederhanakan tanpa menghilangkan esensi dari gelenyu catrik tersebut yang memiliki pancer, kenongan, dan goongan dengan pola iringan yang sama yaitu 2-5.

Beriku adalah salah Etude pembelajaran kacapi kawih Bani Ambara pola iringan gelenyu catrik yang sudah disederhanakan:

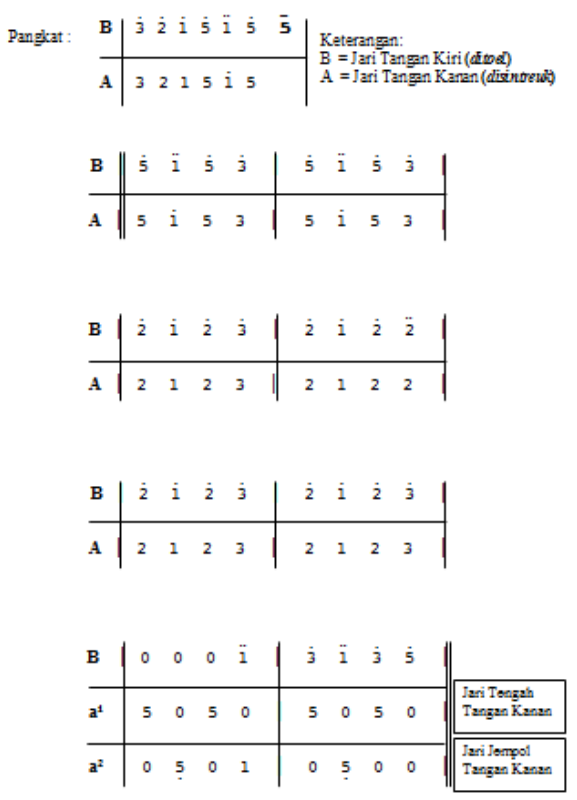

Partitur 2. Etude Pola Pirigan 
Gelenyu Catrik Pembelajaran Kacapi

Kawih Bani Ambara

Dalam etude pola pirigan gelenyu catrik Bani Ambara ini merupakan pola gelenyu yang disederhanakan dan tetap sama memiliki pancer, kenongan, dan goongan yang sama dengan pola iringan 2-5. Perbedaan selanjutnya yaitu dengan disederhanakanya harga nada dimana dalam etude ini harga nada di samakan semua menjadi satu ketukan. Serta dalam bar terakhir merupakan jembatan nada pada pola pirigan catrik.

Dalam memainkan etude gelenyu ini juga sangat disderhanakan dengan cara memainkan dengan teknik di toel untuk jari telunjuk kiri dan teknik disintreuk untuk jari telunjuk kanan dengan pola nada yang disamakan atau disebut dengan sagembyang. Sehingga sangat memudahkan para peserta didik untuk mempelajari kacapi kawih ini dengan singkat karena dengan materi pembelajaran kacapi yang disederhanakan dan dipermudah. Hasil wawancara dengan salah satu siswa SMAN 1 Ciamis yaitu Rizal Hamdani mengatakan:

"Etude kacapi buatan bapak Bani sangat membantu untuk para siswa yang ingin belajar kacapi dari dasar karena Etude nya sederhana sehingga mudah dimengerti" (Wawancara Sepember 2020)

Pada dasarnya Etude pembelajaran kacapi kawih Bani Ambara dibuat karena sesuai dengan kebutuhan dan kemampuan para peserta didik di SMAN 1 Ciamis. Dengan membuat kembali Etude pembelajaran kacapi kawih adaptasi dari Etude kacapi Mang Koko sehingga etude pembelajaran kacapi kawih ini bisa diterima oleh para peserta didik di SMAN 1 Ciamis.

Maka dari itu bahan ajar pembelajaran kacapi kawih Bani Ambara pada mata peajaran Seni budaya di
SMAN 1 Ciamis ini masih digunakan karena kesesuaian antara bahan ajar dan kurikulum serta materi pembelajaran kacapi kawih yang sederhana dan mudah dipahami yang membuat tercapainya kompetensi dasar yang digunakan dalam pembelajaran ini.

\section{Kesimpulan}

Berdasarkan hasil temuan dan pembahasan oleh peneliti, peneliti memperoleh kesimpulan tentang pentingnya kedudukan bahan ajar dalam pembelajaran karena bahan ajar mempunyai fungsi sebagai alat dalam pembelajaran sehingga membantu guru dan peserta didik dalam memudahkan proses pembelajaran dimana dengan dicantumkanya kompetensi dasar dalam bahan ajar, peserta didik menjadi paham akan apa tujuan dari pembelajaran sehingga dengan begitu pesera didik bisa belajar secara mandiri dengan acuan kompetensi dasar yang ada.

Disimpulkan juga bahwa kurikulum memiliki sifat keluwesan dan fleksibel dimana kurikulum tidak bersifat kaku yang artinya dalam implementasinya dapat dikembangkan bedasarkan kreativitas guru, kompetensi, dan disesuaikan dengan kondisi lingkungan sekolah. Hal ini terlihat dari adanya pembelajaran kacapi pada mata pelajaran seni budaya di SMAN 1 Ciamis yang dilandasi oleh kompetensi guru dan tenaga pendidik serta ketersediaan sarana dan prasarana disekolah.

Dilihat dari pemilihan materi dalam pembelajaran kacapi kawih di SMAN 1 Ciamis yaitu tentang teknik memainkan kacapi serta Etude dan pola Pirigan Kacapi dimana maeri tersebut disusun dan dibuat oleh guru Seni budaya di SMAN 1 Ciamis serta Etude yang disedehanakan dari Etude Kacapi Mang Koko sehingga bisa memudahkan para peserta didik dalam mempelajari 
memainkan kacapi dan mencapai kompetensi dasar yang ditentukan.

Maka dari itu bahan ajar pembelajaran Kacapi Kawih ini membuat para peserta didik mampu memainkan alat musik tradisional Jawa Barat ini yakni Kacapi dengan pola pirigan catrik, yang mana pola pirigan catrik ini adalah pola pirigan yang sering digunakan dalam mengiringi kawih sehingga para peserta didik bisa mengimplikasikan materi pembelajaran kacapi ini dengan cukup baik.

\section{Daftar Pustaka}

Alwasiah, AC. 2008. Pokoknya kualitatif. Jakarta: PT Dunia Pustaka Jaya.

Ambara, Bani. 2018. Etude Dasar Pirigan Kacapi Siter Laras Degung Berbasis Pola Gending di SMK BENC Ciamis. Tesis Magister Universitas Pendidikan Indonesia: Tidak Diterbitkan.

Aserani, Kurdi. 2011. Bahan Diklat Seni Budaya Seni Musik. Tanjung: SMKN 1 Tanjung. Bayu, Kurniawan. 2013. Seni Budaya Untuk SMA Kelas XI. Jawa Tengah: Viva Pakarindo.

Fauziah, Suci Dewiyani. 2019. Pembelajaran Kacapi Kawih Pada Mata Pelajaran Seni Budaya di Kelas XI SMAN 1 Ciamis. Skripsi S1 Universitas Pendidikan Indonesia: Tidak Diterbitkan

Fitrah. 2017. Belajar dan Pembelajaran. Jurnal Kajian Ilmu-ilmu Keislaman Vol 3.333-351.

Hadliansyah, Dadang Hermawan. Juwita. 2019. Degung Kawih Wanda Anyar. Tasikmalaya: Edu Publisher.

Ibrahim, R. Nana Syaodin S. 2003. Perencanaan Pengajaran. Jakarta: PT Rineka Cipta

Jalaludin. Abdullah Idi. 2014. Filsafat Pendidikan: Manusia, Filsafat dan Pendidikan Edisi Revisi. Depok: PT Rajagrapindo Persada

Julia. 2007. Pendidikan Musik: Permasalahan dan Pembelajarannya. Sumedang: UPI Sumedang Press

Komalasari, Heni. 2020. Pembelajaran Seni Berbasis Kearifan Lokal di Era Disrupsi. Jurnal Seminar Pendidikan. 1 -2.

Majid, Abdul. 2007. Perencanaan Pembelajaran. Bandung: PT Remaja Rosdakarya.

Makmun, Abin Syamsudin. 1996. Psikologi Kependidikan. Bandung: PT Remaja Rosdakarya

Natapraja, Iwan. 2003. Sekar Gending: Bahasan Karawitan Sunda. Bandung: PT Putra Galuh Pakuah

Rooljakers, Ad. 2005. Mengajar Dengan Sukses. Jakarta: PT Gramedia Widiasara Indonesia. Rusdiana, A. Yeti Heryati. 2015. Pendidikan Profesi Keguruan. Bandung: CV Pustaka

Setiaji, Denden. 2018. Inovasi Musik Kacapi Sebagai Wajah Baru dari Sajian Kesenian Kacapi Kawih. Jurnal Pendidikan Seni Vol 1. 26 - 34

. 2020. Pembelajaran Musik Dengan Pola Pikir Kreative, Inofatif dan Pisioner di Era 4.0. Jurnal Seminar Pendidikan. $1-2$.

Siti, Puja. 2016. Pemahaman Konsep Kurikulum dan Pembelajaran dengan Peta Konsep Bagi Mahasiswa Pendidikan Seni. Jurnal Pendidikan dan Kajian Seni Vol 1. 16 - 28.

Sukardi, M. 2008. Evaluasi Pendidikan. Jakarta Timur. PT Bumi Aksara 